\title{
Brücken bauen
}

\section{Jana Siroka}

Dr. med., Präsidentin VSAO Zürich

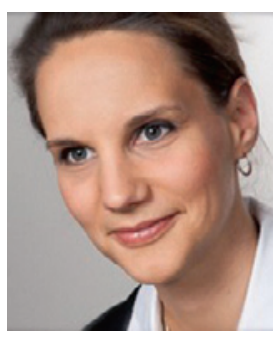

Vom Intergrativmedizin-Spital in Arlesheim bis zur Intensivmedizin am USZ - vom Missionsspital in Zambia bis zur Schweizer Standespolitik hat es mich stets fasziniert, Brücken zu bauen.

Brücken zwischen High-end-Medizin und Drittwelt; Brücken zwischen universitärer und integrativer Medizin. Brücken zwischen Assistenzärzten und Chefärztinnen. Mein erstes Berufsjahr absolvierte ich 2009 auf der Chirurgie in einem Regionalspital. Es lehrte mich, dass ich wohl eher zur Internistin geschaffen bin. So landete ich auf der interdisziplinären Notfallstation - ein Ort, an dem ich mich bis heute zu Hause fühle. Ich wechselte zur Poliklinik USB und durchlief parallel zu einer universitären medizinischen Weiterbildung berufsbegleitend ein dreijähriges anthroposophisches ÄrzteSeminar mit dem Ziel «Fähigkeitsausweis Arzt für anthroposophisch erweiterte Medizin VAOAS/SIWF». Denn mich interessierte schon immer auch die ganzheitliche Betrachtung des Menschen in seiner physischen, seelischen und geistigen Dimension. Daher ist für mich der integrative Ansatz - der Zusammenschluss komplementärmedizinischer und sogenannt schulmedizinischer Ansätze ein befruchtender und weiterführender Weg.

Denn wie sähe es aus ohne die Errungenschaften der modernen "Schulmedizin"? Bald sollte ich dazu mehr erfahren. 2013 zog es mich in ein kleines Missionsspital im ländlichen Sambia. Dort begegnete mir Lebensfreude und gleichzeitig ein Elend, das ich bis heute kaum in Worte fassen kann. Ich erlebte tiefste Ohnmacht als Ärztin und Mensch vor der Not dieser Patienten.

Ich erinnere mich an meine Patienten, wie z.B. das neunjährige Mädchen Daisy, das mit einem angeborenen Ventrikelseptumdefekt keuchend auf dünne Ärmchen gestützt auf dem Stuhl sass - weil sie wegen des Lungenödems nicht mehr flach liegen konnte. Oder der von AIDS und Tuberkulose gezeichnete junge Mann, der voller Glück ein kleines Schälchen mit gekochten grünen Blättern in der Hand hielt. Noch heute bin ich dankbar für jede Mahlzeit in der Spitalkantine. Diese Erfahrungen durchdrangen und veränderten mich. Ich wollte erfahren, wie die Medizin am anderen Ende des Spektrums aussieht.

So ergriff ich nach dem Abschluss in "Innerer Medizin» tensivstationen am Universitätsspital Zürich. Ein ganz anderes Universum - ich erlebte die Welt der Intensivmedizin an einer Klinik mit Weltruf und sah, zu welchen Höchstleistungen Ärzte und Pflegende in Verbindung mit Technik fähig sind. Die Patienten hier durchlebten ganz andere Notlagen - aber sie waren ebenfalls in physischen, seelischen und geistigen Ausnahmesituationen. In dieser existenziellen Lage zwischen Leben und Tod erfuhr ich trotz technischer Höchstleistungen auch immer wieder Dilemmata und Ohnmacht. Auch in diesem aussergewöhnlichen Umfeld haben mich meine Kolleginnen und Kollegen, insbesondere auch die Pflegenden, mit ihrem Engagement, ihrem Sinn für Humor, ihrer Professionalität und Menschlichkeit geprägt.

Die Jahre am USZ haben mich weiter reifen und die Wichtigkeit und den Wert der ethischen Reflektion in der modernen Medizin vertieft wahrnehmen lassen. Auch hier war mir meine Ausbildung in integrativer Medizin von unschätzbarem Wert.

Neben dem praktischen Arztberuf stolperte ich bereits im zweiten Jahr in die Standespolitik. Zuerst als Assistentensprecherin der Poliklinik USB, dann lange Jahre im Vorstand des VSAO Basel und Zürich. Seit 2017 präsidiere ich - fast 5000 Ärztinnen und Ärzte repräsentierend - den VSAO Zürich und erlebe ereignis- und lehrreiche Jahre. Auch hier versuche ich immer, Brücken zu bauen. Brücken zwischen übermüdeten Assistenzärztinnen und von Sachzwängen gedrückten Chefärzten, zwischen der Basis und den CEOs, den Auszubildenden und der FMH/SIWF.

Zuhören, Verständnis für Sachzwänge, Kompromissbereitschaft und manchmal auch Kompromisslosigkeit sind meine Werkzeuge.

Aber auch diese Etappe ist bald zu Ende: Mitte Jahr gebe ich wegen eines beruflichen Wechsels weg von Zürich das Präsidium ab. Meine Kolleginnen und Kollegen des VSAO Zürich und mein Notfall-Team Hirslanden Zürich werde ich vermissen!

Gleichzeitig freue ich mich darauf, bald an der integrativmedizinischen Klinik Arlesheim am Aufbau einer Intermediate Care Station mitzuwirken und diese mit dem Notfall zusammen zu leiten. So bin ich wieder in der Region Basel, mitten in meinen Lieblingsdisziplinen und zugleich am Schweizer Zentrumsspital für anthroposophische Medizin - idealer Ort, um weiter Brücken zu bauen. 